\title{
SUDDEN BILATERAL ISCHAEMIC OPTIC NEUROPATHY IN A YOUNG INDIVIDUAL WITH HYPERHOMOCYSTEINAEMIA: A CASE REPORT
}

\author{
Santosh Patil ${ }^{1}$, Annu Joon ${ }^{2}$, M. R. Pujari ${ }^{3}$, Vishwanath Reddy ${ }^{4}$
}

\section{HOW TO CITE THIS ARTICLE:}

Santosh Patil, Annu Joon, M. R. Pujari, Vishwanath Reddy. "Sudden Bilateral Ischaemic Optic Neuropathy in a young individual with Hyperhomocysteinaemia: A Case Report". Journal of Evolution of Medical and Dental Sciences 2014; Vol. 3, Issue 62, November 17; Page: 13759-13764, DOI: 10.14260/jemds/2014/3838

ABSTRACT: Non-arteritic anterior ischaemic optic neuropathy (NAION) is typically a disorder of older patients who have predisposing risk factors. It is the most common acute optic neuropathy in patients over the age of 50.1,2 Occasionally, NAION occurs in younger patients in the absence of conventional vascular risk factors such as hypertension, hyperlipidaemia, tobacco use, and diabetes. An elevated level of plasma homocysteine is associated with an increased risk of cerebrovascular, cardiovascular, or peripheral vascular disease before 50 years of age..$^{3-5}$ The risk of NAION due to hyperhomocysteinemia is independent of other risk factors like diabetes and hypertension. We hereby report a case of a young individual who developed NAION due to hyperhomocysteinemia in the absence of other risk factors.

KEYWORDS: Non-arteritic anterior ischaemic optic neuropathy (NAION), hyperhomocysteinemia.

CASE REPORT: A 43-year old male presented with complaint of sudden painless loss of vision in the right eye (RE) since four days. On examination, best corrected visual acuity (BCVA) of right eye was finger counting at two metres. Anterior segment evaluation revealed relative afferent pupillary defect. Posterior segment examination showed diffuse pallor and oedema of the optic disc with superotemporal peripapillary haemorrhages. Visual field testing by standard automated perimetry (SAP) demonstrated an inferior altitudinal field defect and OCT for RNFL analysis showed normal RNFL thickness in all quadrants except upper temporal quadrant which showed thinning. Left eye(LE) examination was normal with BCVA of 6/9.

Figure 1: Fundus photograph RE showing pale oedematous optic disc with peripapillary disc haemorrhages.

Figure 2: Fundus photograph LE showing normal fundus.

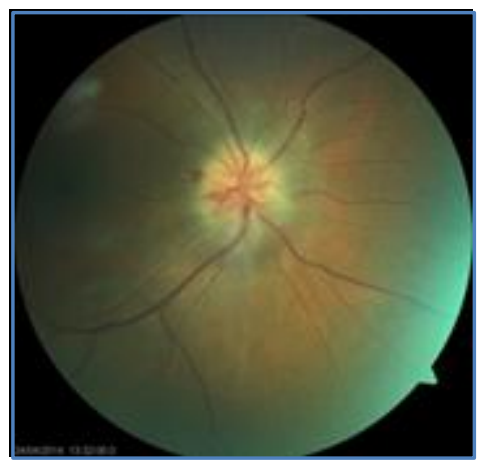

Figure 1

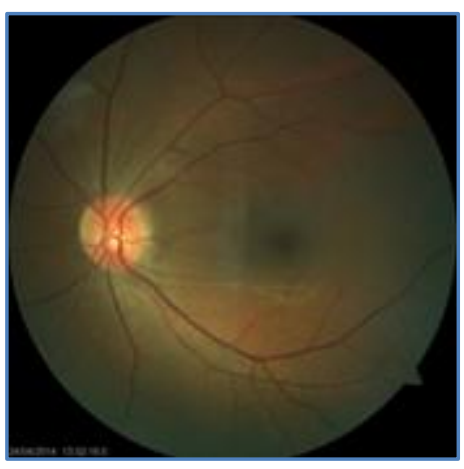

Figure 2 
Figure 3: RE visual field demonstrating inferior altitudinal field defect.

Figure 4: LE visual field within normal limits.

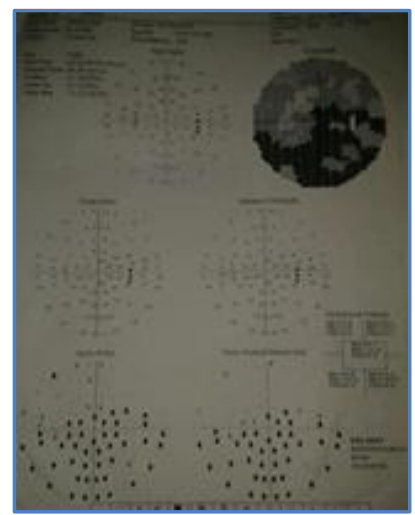

Figure 3

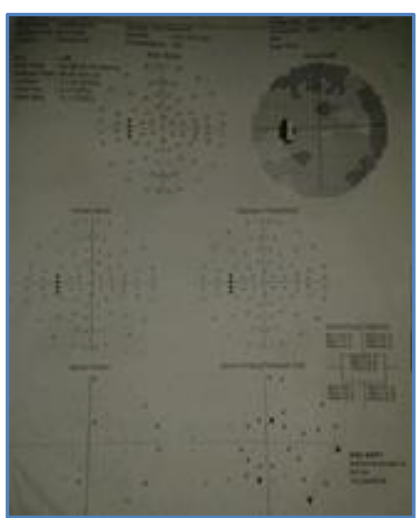

Figure 4

Figure 5: OCT RE revealing normal RNFL thickness in all quadrants except upper temporal quadrant which shows thinning.

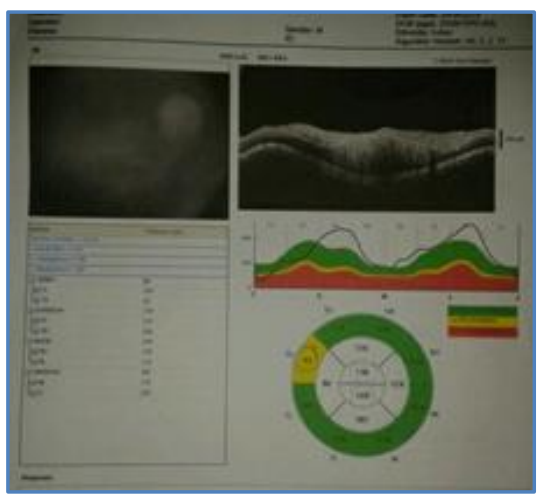

Figure 5

The patient was non-diabetic, normotensive and a non-smoker. Blood investigations like complete blood count, erythrocyte sedimentation rate, C-reactive protein, lipid profile and antinuclear antibody profile were within normal limits. MRI brain with orbit and carotid doppler study was normal. The blood homocysteine levels were found to be elevated [28.56 micromol/L by Chemiluminescent Microparticle Immuno Assay test (CMIA) (normal reference value for males: 5.4616.20 micromol/L)]. However, there was no history of previous ischemic cardiovascular, cerebrovascular or peripheral vascular events.

The patient was diagnosed to have non-arteritic anterior ischaemic optic neuropathy secondary to hyperhomocysteinemia. He was started on intravenous methylprednisolone $1 \mathrm{gm}$ which was given daily for five days. Visual acuity of right eye on the fifth day showed no improvement.

The patient was subjected to further investigations like protein $C$ and protein $S$ levels, sleep study and immunological profile for collagen vascular disorders; all of which were reported to be within normal limits. He was then discharged on oral Folic acid, Pyridoxine and Methycobalamin. The patient was however lost to follow-up. 
Two months later, the patient came back with complaint of sudden painless diminution of vision in left eye. On examination, visual acuity of left eye was 6/12 with no improvement. Anterior segment was normal, and posterior segment demonstrated segmental disc pallor in superior half of the disc. Left eye visual fields by SAP showed inferior altitudinal field defects and OCT for RNFL analysis showed RNFL thinning in all quadrants except lower temporal and infero-temporal quadrants which had normal thickness.

Right eye examination demonstrated deterioration in the BCVA to finger counting at 1metre, relative afferent pupillary defect and total optic atrophy. Right eye visual field testing could not be done due to poor vision. OCT revealed RNFL thinning in all quadrants except lower nasal quadrant which had normal thickness. On enquiry, the patient revealed having discontinued the prescribed oral medications.

Figure 6: Fundus photograph RE with total optic atrophy.

Figure 7: Fundus photograph LE showing segmental disc pallor in superior half of the disc.

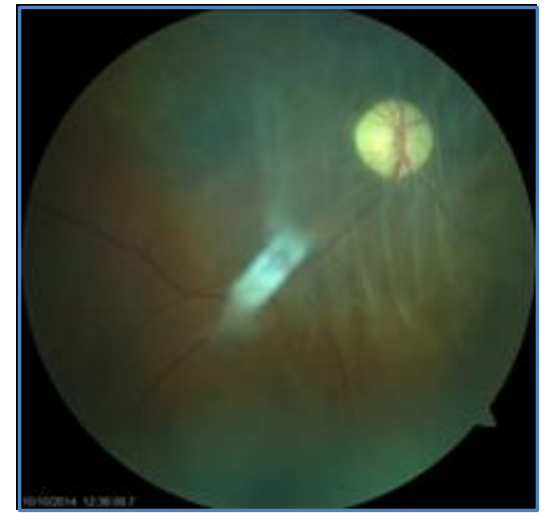

Figure 6

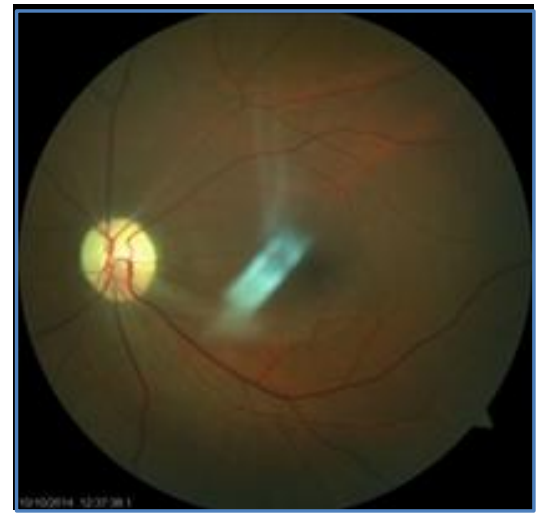

Figure 7

Figure 8: SAP of left eye after two months showing inferior altitudinal field defect.

Figure 9: Two month follow-up OCT showing RNFL thinning in both eyes.

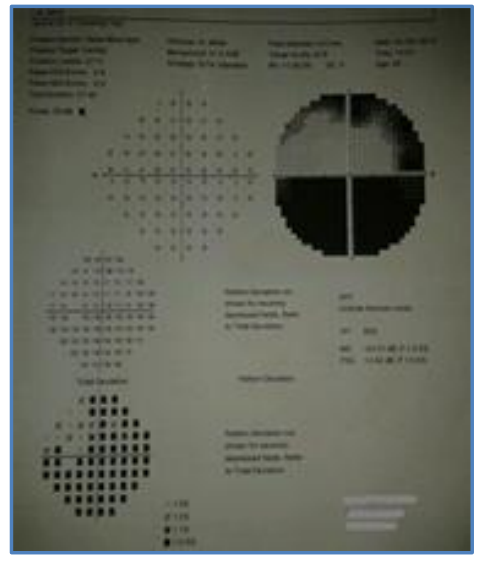

Figure 8

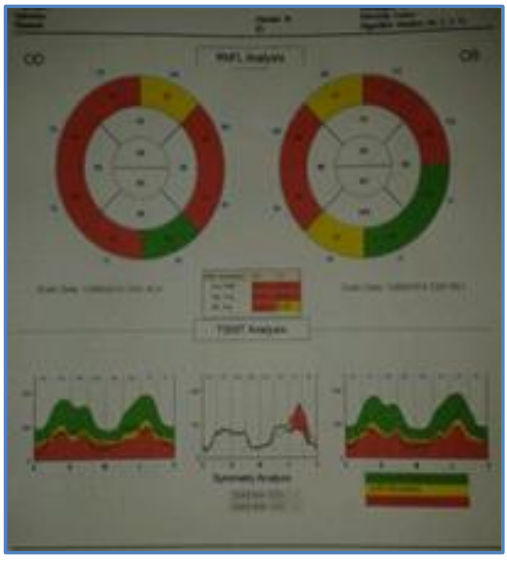

Figure 9 
He was restarted on oral Folic acid, Pyridoxine and Methylcobalamin supplementation; oral corticosteroids were also added to the treatment regime. The patient has been on a regular monthly follow up since then. The right eye and left eye parameters have remained unchanged over the past four months.

Figure 10, 11: Left eye SAP and OCT at four month follow-up showing no further progression.

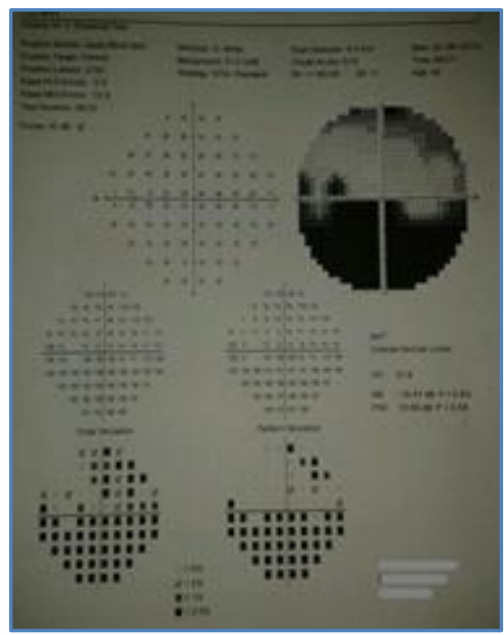

Figure 10

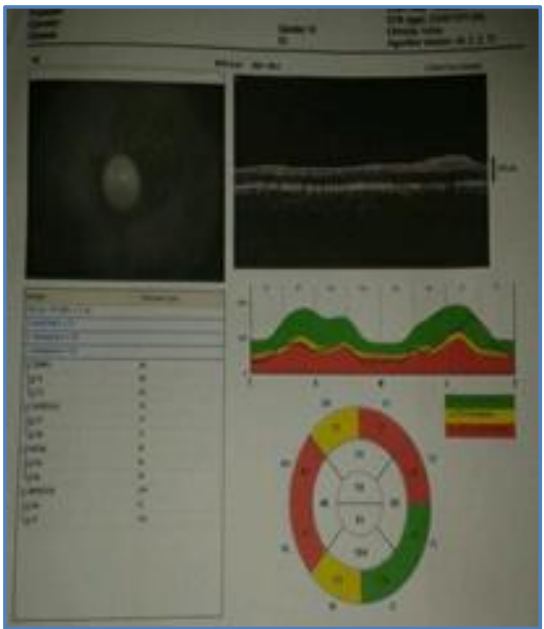

Figure 11

DISCUSSION: Homocysteine is an intermediary amino acid formed during the conversion of amino acid methionine to cysteine in the methionine trans-sulphuration pathway. The enzymes in the transsulphuration and remethylation pathway require vitamin B6, vitamin B12 and folic acid as co-factors. When there is either a genetic disorder causing an enzyme defect or a nutritional deficiency of a vitamin co-factor (B6, B12, folic acid), homocysteine accumulates in the plasma. $6-8$

Elevated plasma homocysteine levels are associated with an increased risk of premature ischaemic events (peripheral vascular disease, stroke, and myocardial infarction) in patients younger than 50 years of age (The clinical use of the term "young" is generally defined in the stroke literature as age less than 50-55 years ${ }^{9}$ ). The prevalence of hyperhomocysteinemia in the general population is estimated at $5 \%{ }^{6}$, a figure that increases to $20-30 \%$ in non-diabetic stroke or myocardial infarction patients younger than 55 years of age.4,10,11 Hyperhomocysteinemia has also been implicated as a cause of retinal artery and retinal vein occlusions in young patients. ${ }^{12,13}$ However, the mechanism of vasculopathy related to hyperhomocysteinaemia remains unclear.

There have been anecdotal reports of thrombotic tendencies in patients with NAION.14-16 However; the relation of hyperhomocysteinaemia to NAION remains unclear. Although Pianka et al ${ }^{17}$ reported elevated levels in $45 \%$ of 40 NAION patients (mean age 66 years) v/s $9.8 \%$ of controls, and Wegeret et al ${ }^{18}$ also reported mean elevation $(11.8 \mathrm{v} / \mathrm{s} 9.8 \mu \mathrm{mol} / \mathrm{l})$ in $59 \mathrm{NAION}$ patients $\mathrm{v} / \mathrm{s}$ controls, Biousseet al ${ }^{19}$ reported normal values in $14 / 14$ patients with a mean age of 43 years. The clinical significance of these statistically significant findings is uncertain, limited by small patient numbers and widely varying results (0/14 in Biousseet al ${ }^{19}$ to $45 \%$ in Pianka et al. $\left.{ }^{17}\right)$ 
NAION is most probably related to local factors compromising the posterior ciliary artery circulation at the optic nerve head (known as the "disc at risk"). It is also possible that systemic factors such as hyperhomocysteinemia may enhance local atherogenesis at the level of posterior ciliary arteries, thereby precipitating the development of NAION.15-16, 20-21

Laboratory testing for hypercoagulable states in a patient with NAION without past medical history or family history of a thrombotic event is routinely unwarranted. ${ }^{14,16,20}$ However, it should be considered in patients who develop NAION in the absence of underlying risk factors such as older age, diabetes, hypertension, or tobacco use. It should also be considered in young patients with bilateral or recurrent attacks of NAION.

\section{REFERENCES:}

1. Hattenhauer MG, Leavitt JA, Hodge DO, Grill R, Gray DT. Incidence of nonarteritic anterior ischemic optic neuropathy. Am J Ophthalmol1997; 123: 103-107.

2. Johnson LN, Arnold AC. Incidence of nonarteritic and arteritic anterior ischemic optic neuropathy: population-based study in the State of Missouri and Los Angeles County, California. J Neuroophthalmol1994; 14: 38-44.

3. D'Angelo A, Selhub J. Homocysteine and thrombotic disease. Blood 1997; 90:1-11.

4. The European Concerted Action Project. Plasma homocysteine as a risk factor for vascular disease. JAMA 1997; 277:1775-81.

5. Boushey CJ, Beresford SAA, Omenn GS, et al. Plasma homocysteine as a risk factor for vascular disease. JAMA 1995; 274:1049-57.

6. Selhub J, Jacques PF, Wilson PWF, et al. Vitamin status and intake as primary determinants of homocysteinemia in an elderly population. JAMA 1993; 270: 2693-8.

7. Engbersen AMT, Franken DG, Boers GHJ, et al. Thermolabile 5, 10-methylenetetrahydrofolate reductase as a cause of mild hyperhomocysteinemia. Am J Hum Genet 1995; 56: 142-50.

8. Jacques PF, Bostom AG, Williams RR, et al. Relation between folate status, a common mutation in methylenetetrahydrofolate reductase, and plasma homocysteine concentrations. Circulation 1996; 93: 7-9.

9. Kawasaki A, Purvin VA, Burgett RA. Hyperhomocysteinaemia in young patients with nonarteritic anterior ischaemic optic neuropathy. Br J Ophthalmol1999; 83: 1287-1290.

10. Mayer EL, Jacobsen DW, Robinson K. Homocysteine and coronary atherosclerosis. J Am CollCardiol1996; 27: 517-27.

11. Clarke R, Daly L, Robinson K, et al. Hyperhomocysteinemia: an independent risk factor for vascular disease. $N$ Engl J Med 1991; 324: 1149-55.

12. Wenzler EM, Rademakers AJJM, Boers GHJ, et al. Hyperhomocysteinemia in retinal artery and retinal vein occlusion. Am J Ophthalmol1993; 115: 162-7.

13. Biousse V, Newman NJ, Sternberg P Jr. Retinal vein occlusion and transient monocular visual loss associated with hyperhomocystenemia. Am J Ophthalmol1997; 124: 257-60.

14. Hayreh SS. Acute ischemic disorders of the optic nerve. Pathogenesis, clinical manifestations and management. OphthalmolClin N Am 1996; 9: 407-42.

15. Biousse V. Coagulation disorders and their neuro-ophthalmologic manifestations. CurrOpinOphthalmol1999; 10: 382-93. 
16. Salomon O, Huna-Baron R, Kurtz S, et al. Analysis of prothrombotic and vascular risk factors in patients with nonarteritic anterior ischemic optic neuropathy. Ophthalmology 1999; 196: 73942.

17. Pianka P, Almog Y, Man O, Goldstein M, Sela BA, Loewenstein A. Hyperhomocysteinemia in patients with nonarteritic anterior ischemic optic neuropathy, central retinal artery occlusion, and central retinal vein occlusion. Ophthalmology 2000; 107: 1588-1592.

18. Weger M, Stanger O, Deutschmann H, Simon $M$, Renner W, Schmut 0 et al. Hyperhomocysteinemia, but not MTHFR C677T mutation, as a risk factor for non-arteritic anterior ischaemic optic neuropathy. Br J Ophthalmol2001; 85: 803-806.

19. Biousse V, Kerrison JB, Newman NJ. Is non-arteritic anterior ischaemic optic neuropathy related to homocysteine? Br J Ophthalmol 2000; 84: 554.

20. Lee AG. Prothrombotic and vascular risk factors in nonarteritic anterior ischemic optic neuropathy. Ophthalmology 1999; 12: 2231.

21. Ischemic Optic Neuropathy Decompression Trial Research Group. Characteristics of patients with nonarteritic ischemic optic neuropathy eligible for the Ischemic Optic Neuropathy Decompression Trial. Arch Ophthalmol1996; 114: 1366-74.

\section{AUTHORS:}

1. Santosh Patil

2. Annu Joon

3. M. R. Pujari

4. Vishwanath Reddy

\section{PARTICULARS OF CONTRIBUTORS:}

1. Associate Professor, Department of Ophthalmology, Basaveshwar Teaching and General Hospital, Attached to M. R. Medical College, Gulbarga.

2. Post Graduate, Department of Ophthalmology, Basaveshwar Teaching and General Hospital, Attached to M. R. Medical College, Gulbarga.

3. Professor and HOD, Department of Ophthalmology, Basaveshwar Teaching and General Hospital, Attached to M. R. Medical College, Gulbarga.
4. Professor, Department of Ophthalmology, Basaveshwar Teaching and General Hospital, Attached to M. R. Medical College, Gulbarga.

\section{NAME ADDRESS EMAIL ID OF THE CORRESPONDING AUTHOR:}

Dr. Annu Joon,

Post Graduate,

Department of Ophthalmology,

Basaveshwar Teaching and General Hospital.

Email: annujoon@gmail.com

Date of Submission: 31/10/2014.

Date of Peer Review: 03/11/2014.

Date of Acceptance: 12/11/2014.

Date of Publishing: 17/11/2014. 